\title{
Interview with Jørgen Abild Andersen, Chairman of Committee on Digital Economy Policy (CDEP) of OECD, the Organisation for Economic Co-operation and Development
}

\author{
Knud Erik Skouby and Anders Henten \\ Center for Communication, Media and Information technologies, Aalborg \\ University, Denmark
}

Received: December 2013; Accepted: January 2014

\begin{abstract}
In the interview, Jørgen Abild Andersen explains how he has been working on changing the agenda of ICCP (now CDEP) in OECD. Formerly, the Committee has worked with issues centered on the development and growth of information and communication technologies (ICTs) without much attention to the use and implications in other sectors of society. This may have been relevant in a period when telecommunications and broadcasting have been liberalized. However, today, more attention needs to be paid to the great societal challenges regarding better lives and economic growth. At the end of the interview, Jørgen Abild Andersen also addresses issues relating to Internet governance.

First we would like to ask you about the major challenges today, and in the coming years, for the ICT area and how CDEP approaches and works with these challenges.

JAA: There are, obviously, many challenges. One of the most prominent ones is related to the structure and sub-structure of the Committee itself. At a Committee meeting in December 2013 two very important decisions were made. One regarding the name of the Committee. It was changed from Committee on Information, Communications and Computer Policy (ICCP) to Committee
\end{abstract}

Journal of NBICT, Vol. 1, 139-146.

doi: 10.13052/NBICT.2015.006

(C) 2015 River Publishers. All rights reserved. 
on Digital Economy Policy (CDEP) mainly in order to better reflect what is at the core of the work of the Committee. Another decision concerned the substructure. One of the working parties that have existed for many years is the Working Party on Communications Infrastructure and Services Policy (CISP). This is the one that has been working with infrastructure issues and during the years has produced a vast amount of reports and benchmarks regarding the ICT area. Then there has been a Working Party on Information Security and Privacy (WPISP). This is a very crucial area of activity for OECD. Furthermore, there has been a Working Party on Indicators on the Information Society (WPIIS). I have always thought that this is a very important working area, as this is one of the ways to document whether the policies implemented actually have the right effect. At the meeting in December CDEP decided to maintain these three working parties by prolonging their mandate until the end of 2016. The fourth working party, the Working Party on the Information Economy (WPIE), has over the years been dealing with cross-cutting issues, increasingly with a substantial and strategic flavour which would rather belong to the Committee itself. In order to increase efficiency, avoid duplication of work and bring back substantive and strategic discussions to the Committee the Committee meeting in December decided to merge the majority ogf WPIE tasks into the CDEP. The remaining tasks which to some extent have been overlapping with tasks carried out by WPIIS will be transferred to that working party.

But these are organizational technicalities. My ambition as the chair of $\mathrm{CDEP}$ has been to align the work of CDEP with the general, horizontal goals of OECD. CDEP must be a building block in the overall OECD construction. And, when the OECD has a cross-sectoral project entitled New Sources of Growth, the specialized committees should contribute to achieving this overall aim. The overall aim is to secure jobs and growth under the heading of 'better lives'. This is, of course, a very general goal. But my ambition, as chair of CDEP, is to spot such general goals and to find out how the CDEP can contribute to this. And, with New Sources of Growth, the CDEP has become responsible for the issue of 'big data'. 'Big data' is - as you know - the raw material for many services and applications with enormous economic potentials. Graham Vickery (previous employee of OECD) has in the EU context been responsible for a project on the economic implications of setting public data 'free', i.e. to use them for new services and applications. The conclusion was that for the EU-27 countries, setting data free has a direct and indirect annual value of Euro bio. 140. In the country-regionUS, where the restrictions on the use of data are not as strict as in Europe, almost 500,000 new jobs have in few years been created in the app industry which has become 
a 20 billion dollars industry. There are thus great potentials in terms of jobs and growth in 'big data'. In the European Union context, work on Public Service Information (PSI) has been going on for many years now, but the whole issue of 'big data' is much broader and the potentials are far greater.

Another issue that is increasingly becoming important is the so-called 'silver economy', the economic implications of aging populations. Together with Waseda University in Tokyo CDEP held a workshop in 2012 on ICTs and the Silver Economy. ICTs can be used to address a number of the issues related to aging populations. ICTs can help in connection with the elderly staying longer on the labor market. ICTs can also address health care issues. In Japan, the elderly constitute a growing part of the population, which incidentally leads to a growing number of people with Alzheimer. And here, 'big data' can be of great help. It can facilitate early diagnosis of Alzheimer by spotting changes in the behavior of aging persons. Are there, for instance, significant changes in the ways credit cards of a person are used or are there changes in the use of electricity? All this can be indications of a beginning Alzheimer disease. There are obviously privacy issues at stake here, but if we look at the potentials, they are enormous, and I'm sure that this increasingly will come on the political agendas around the world. Not only are there strong human factors, but the economic potentials are huge in terms of health cost saving and new business potentials.

This points at a very important question, namely how societies can benefit more from all kinds of usages of ICTs. How is it that this is being taken up by the OECD?

JAA: This is exactly what we are working on promoting in the OECD. The council of OECD has asked for a clearer 'roadmap' for the activities of CDEP, and once such a call for a clearer direction of activities is made, there is a good opportunity for redirecting and sharpening activities. In the work program for 2015-16, a Ministerial Meeting on the subject of maximizing the benefits of the Internet economy is scheduled. The aim is to put on the agenda all the different social benefits that Internet help support. A central concept in this connection is what is being called a 'whole of government approach', meaning that all the different areas of government policies should been seen in the light of the potentials of using Internet. Very crucial is the involvement of the ministries of finance. They are in a central position in all governments, and to get them involved is of great importance.

This means that the traditional areas of work looking at more specific topics related to the development of ICTs and the communications infrastructures 
should be seen in light of the big agendas regarding better lives and economic growth. Activities of a more limited character should be prioritized according to how they support the overall agendas. And, this is where 'big data' is a very good example. Not only can new applications and services be developed, but it can also help in connection with the large societal challenges. It's only during the past few years that this, to a large extent, has penetrated the work of CDEP.

Is there a general support for this change of agenda of the work of CDEP?

JAA: There is a general understanding that this is the right way to go. Important countries like Germany and France, for instance, are increasingly pushing for this change of agenda. But there is still a long way to go. The work of CDEP needs to gain more visibility to attract funds, of course, but also the involvement of high-ranking officials of the member countries. There is a need for the CDEP to leave the type of work where specialists of specific topics meet to talk about limited issues without any great implications for the broader agenda. We need to be more focused in our work on topics which have a clear and positive impact on the agendas of our political masters. I think that we are going in the right direction and that there is a growing realization that ICTs and the use of ICTs needs to be put in a wider social framework.

Japan is a very good example of this. Japan may not in terms of telecom reforms be the most advanced country. However, if we look at issues relating to the 'silver economy' and the use of ICTs, many things are happening in Japan. At the Waseda University in Tokyo, for example, a lot of important work is going on, which could be inspirational to research in many other countries.

Is it possible for the OECD to point at specific areas of prioritization? In all countries, there is an awareness that we need to look at how ICTs can support the solutions to the large societal challenges. But it can be difficult to prioritize. How can OECD and CDEP work with discussing the priorities?

JAA: I believe that it's important to determine a baseline for your work and then also to measure the results of it. I have always given great emphasis to measuring results of policy initiatives. This applies, for instance, when the EU Commissioner Neelie Kroes publishes figures on the share of productivity growth that comes from ICT use. It also applies to figures on jobs created in the apps industry in the US. And, it applies when McKinsey calculated that every time ICTs make 1 person redundant, 2.6 new jobs are created. This means that ICTs do no reduce but increase employment, and we are here talking about well-paid jobs and high contributions to GDP growth. It's highly important to look at the overall economic implications of the use of ICTs. This will be 
the basis for determining what should be prioritized in terms of ICT related policies.

Could we also finally talk about a narrower though very important field that we know you are working with, namely Internet governance.

JAA: Yes, in 2011 the OECD Council made a recommendation regarding Principles for Internet Policy Making. This was a recommendation initiated mainly by the Americans. The aim was to establish a set of "best in class"-principles for Internet Policy Making based on which principles had proven successful for the development of the internet in countries around the world. One of the principles reflects the multistakeholder approach for Internet Governance which over the years has brought about very successful results regarding the development of the internet - an approach and a principle which has been the anchor stone of ICANN, the Internet Corporation for Assigned Names and Numbers. The OECD commitment to the multistakeholder approach has emerged while at the same time we have seen growing concern from some governments and other stakeholders that Internet governance should be organized differently from what it is today. The International Telecommunication Union, ITU, could, for instance, have a larger say. Internet governance should, to a larger extent, represent other than US centric interests. This was more or less the message - conveyed in more diplomatic phrasing - which was delivered by a majority of countries at the ITU's WCIT conference in December 2012 in Dubai. There is clearly an issue here. Following an agreement (a so called Affirmation of Commitments) between the US Department of Commerce and ICANN, there is every three years a review of accountability and transparency issues related to ICANN. This time, I have participated in the review team. Formally not representing anyone but informally of course I cannot deny my long time career in the Danish Civil Service.

It's my observation that there is not a great willingness to take the problems of accountability in relation to the rest of the world sufficiently serious in ICANN. They do not seem to be aware that they are sitting on a burning platform, where other than US interests need to be taken into account. More inclusion is needed. Only a very small percentage - app. 2-3 pct. - of applications for new generic Top Level Domains (gTLDs), for instance, came from stakeholders in Africa and Latin America. May be even more serious is the poor level of participation from outside the US in the Policy Development Process (PDP) of ICANN. More than 80 pct. of participants come from the US. This illustrates the skewed nature of Internet governance that needs to be addressed. Also, and still in relation to gTLDs: This can become a very 


\section{Knud Erik Skouby and Anders Henten}

important source of considerable income for ICANN, which is supposed to be a non-profit organization. This certainly calls for increased transparency with respect to the finances of ICANN. I think that it is important to understand that the Internet would never have developed to the stage it is at today had it been regulated by traditional telecommunication regulation. I, therefore, think that there are great advantages in continuing with a multistakeholder driven governance model.. It is, however, important to understand that the Internet has grown far beyond the boundaries of the US and that stakeholders outside the US should have a larger say to maintain the legitimacy of the current multistakeholder model.

In the OECD we are very concerned about keeping the momentum with respect to the development of the internet to the benefit of innovation, growth and new jobs. It is therefore with great concern we are following the discussions regarding internet governance which really took off at the WCIT conference. These discussions will continue and an important event in that respect to be followed with particular interest will be the ITU Plenipotentiary Conference in Korea in the autumn of 2014.

\section{Biographies}

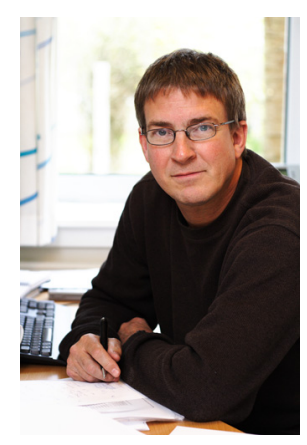

Anders Henten is Professor with special responsibilities at center for Communication, Media and Information technologies (CMI) at the Department of Electronic Systems at Aalborg University in Copenhagen. He is a graduate in communications and international development studies from Roskilde University in Denmark (1989) and holds a Ph.D. from the Technical University of Denmark (1995). He has worked professionally in the area of communications economy and policy for more than 25 years. He has participated in numerous research projects financed e.g. by the European Community, the Nordic 
Council of Ministers, Danish Research Councils and Ministries, and in consultancies, financed by World Bank, UNCTAD, ITU, Danish Ministries, etc. He has published nationally and internationally - more than 250 academic publications in international journals, books, conference proceedings, etc.

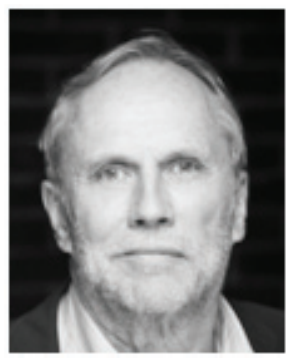

Knud Erik Skouby is professor and director of center for Communication, Media and Information technologies, Aalborg University-Copenhagen. Has a career as a university teacher and within consultancy since 1972. Working areas: Techno-economic Analyses; Development of mobile/ wireless applications and services: Regulation of telecommunications.

Project manager and partner in a number of international, European and Danish research projects. Served on a number of public committees within telecom, IT and broadcasting; as a member of boards of professional societies; as a member of organizing boards, evaluation committees and as invited speaker on international conferences; published a number of Danish and international articles, books and conference proceedings. Board member of the Danish Independent Research Council and the Danish Media Committee. Chair of WGA in Wireless World Research Forum; Special Advisor to GISFI; dep chair IEEE Denmark. 
